\title{
Small and dense LDL in familial combined hyperlipidemia and N29 IS polymorphism of the lipoprotein lipase gene
}

\author{
Antonio López-Ruiz*1, María M Jaraboํ, María L Martínez-Triguero², \\ Maria Morales-Suárez-Varela ${ }^{3}$, Eva Solá ${ }^{1,4}$, Celia Bañuls ${ }^{1,3}$, Marta Casado ${ }^{5}$ and \\ Antonio Hernández-Mijares $1,3,4$
}

Address: ${ }^{1}$ Service of Endocrinology, University Hospital Dr Peset, Valencia, Spain, 2 Service of Clinical Analysis, University Hospital La Fe, Valencia, Spain, ${ }^{3}$ CIBER CB/06/02/0045 research group, CIBER Actions in Epidemiology and Public Health, Valencia, Spain, ${ }^{4}$ Medicine Department, University of Valencia, Valencia, Spain and 5 Institute of Biomedicina of Valencia (CSIC), CIBERehd, Valencia, Spain

Email: Antonio López-Ruiz* - alru63@hotmail.com; María M Jarabo - jarabo_mar@gva.es; María L Martínez-

Triguero - martinez_mlutri@gva.es; Maria Morales-Suárez-Varela - maria.m.morales@uv.es; Eva Solá - sola_eva@gva.es;

Celia Bañuls - Celia.Banuls@uv.es; Marta Casado - mcasado@ibv.csic.es; Antonio Hernández-Mijares - hernandez_antmij@gva.es

* Corresponding author

Published: 31 March 2009

Lipids in Health and Disease 2009, 8:12 doi:10.1186/1476-5IIX-8-12

This article is available from: http://www.lipidworld.com/content/8////2

(C) 2009 López-Ruiz et al; licensee BioMed Central Ltd.

This is an Open Access article distributed under the terms of the Creative Commons Attribution License (http://creativecommons.org/licenses/by/2.0), which permits unrestricted use, distribution, and reproduction in any medium, provided the original work is properly cited.
Received: 12 january 2009

Accepted: 31 March 2009

\begin{abstract}
There is a predominance of small and dense LDL cholesterol particles in familial combined hyperlipidemia $(\mathrm{FCH})$. The lipoprotein lipase gene could exert an influence in these circumstances.

To study the relationship of pattern B LDL and lipids with N29IS polymorphism of lipoprotein lipase (LPL) in FCH patients.

Lipid profile, apolipoproteins, diameter of LDL and N29IS polymorphism were determined in 93 patients with $\mathrm{FCH}$ and 286 individuals from the general population.

$\mathrm{FCH}$ patients with N29IS polymorphism showed a lower mean diameter of LDL. FCH patients with pattern B LDL showed higher concentrations of triglycerides, VLDLc, non-HDLc and apo $\mathrm{BI} 00$ and lower levels of HDLc than those with pattern A. Of $\mathrm{FCH}$ patients with polymorphism $87.5 \%$ presented pattern $B$ and $12.5 \%$ pattern $A$, while patients without polymorphism presented pattern $A$ in $69.2 \%$ cases and pattern $B$ in $30.8 \%$ cases, with differences being statistically significant $(p<0.004)$. The prevalence of this mutation in our $\mathrm{FCH}$ patients was $9.7 \%$.

The prevalence of N29IS mutation in our $\mathrm{FCH}$ patients was similar to the $9.3 \%$ described in Dutch $\mathrm{FCHL}$ patients but clearly higher than the $2-5 \%$ described for other Caucasian populations. No polymorphism was found in our general population sample. $\mathrm{FCH}$ patients with phenotype $\mathrm{B}$ of LDL possessed an atherogenic lipid profile. The relationship between small and dense LDL and the presence of the N29IS mutation may identify patients with high cardiovascular risk.
\end{abstract}

\section{Background}

A common form of dyslipemia associated with insulin resistance (obesity, diabetes mellitus, familial combined hyperlipidemia) is constituted by the presence of the atherogenic lipoprotein phenotype, characterized by elevated levels of triglycerides, small LDL particles and reduced HDL cholesterol [1]. This lipid triad frequently occurs in patients with premature coronary disease [2]. 
Small and dense LDL particles are formed largely as a response to high levels of triglycerides, and increase the risk of coronary heart disease [3]. LDL particles show a bimodal distribution in peak size and can be separated into two phenotypes; pattern $\mathrm{A}$, in which larger, more buoyant LDL predominate, and pattern $\mathrm{B}$, in which smaller, more dense LDL predominate. The National Cholesterol Education Program (ATP III) considers small and dense LDL as a lipid risk factor.

Familial Combined Hyperlipidemia (FCH; MIM 144250) is the most frequent genetic hyperlipemia. It is characterized by a tendency towards the appearance of coronary disease before 60 years of age [4]. The prevalence of this disease is 1$2 \%$ in the general population [5] and $10-20 \%$ among patients with premature coronary disease [6]. FCH presents a complex phenotype that is not completely understood, and which can vary between the patient and affected relatives [7]. Therefore, it is difficult to diagnose. It is also characterized by the presence of the atherogenic lipoprotein phenotype and an increase in apolipoprotein B100 [8].

Several genes have been studied in relation with $\mathrm{FCH}$, which is a polygenic disease. One of the genes involved in FCH is lipoprotein lipase (LPL, E.C. 3.1.1.34) [9], a glycoproteic enzyme that plays a key role in the catabolism of lipoproteins rich in triglycerides, such as chylomicrons, and very low density lipoproteins (VLDL). LPL action takes place in endothelial cells surrounding the lumen of capillary vessels, where it adheres to heparan sulphate proteoglycans [10].

More than 80 structural mutations have been detected within the LPL gene. The frequency of these mutations in the general population is estimated to be at least $1 / 500$. These heterozygous mutations are the main cause of some lipid disorders. One of these mutations is N291S localized in exon 6 of LPL [11-13].

The aim of our study was to analyze the relationship of the atherogenic lipoprotein profile, especially the predominance of small and dense LDL, with the prevalence of N291S LPL polymorphism in Spanish patients with FCH from the Community of Valencia with respect to with the general population.

\section{Materials and methods}

Our study sample consisted of 33 families with Familial Combined Hyperlipidemia (FCH), with a mean of 4.4 individuals per family, all of them living in the Autonomous Community of Valencia (SE of Spain). From a total of 146 subjects, 93 were diagnosed with FCH according to the criteria of Bredie SJ et al. [14]. Total cholesterol and triglycerides levels superior to the $90^{\text {th }}$ percentile (adjusted to age and gender) and apo B100 values superior to $1.2 \mathrm{~g} / \mathrm{L}$ represented a diagnosis of $\mathrm{FCH}$ in 43 men and 50 women, aged from 15 to 75 years. In order to assess polymorphism in the general population, 286 genetically independent healthy controls of similar gender and age were randomly selected.

Venous blood was collected for biochemical measurements. Total cholesterol (TC) and triglycerides (TG) were measured through enzymatic methods and high density lipoproteins cholesterol (HDLc) using a direct method in a Beckman LX20 auto analyzer. The intraserial variation coefficient was $<3.5 \%$ for all these determinations. When TG values were under $400 \mathrm{mg} / \mathrm{dL}$, LDL cholesterol concentration was calculated using Friedewald's formule [15]. Non-HDL cholesterol was obtained from the difference between total cholesterol and HDL cholesterol. Apolipoproteins AI and B100 were determined by immunonephelometry in a Dade Behring BNII (intra-assay variation coefficient $<5.5 \%$ ).

LDL B phenotype was measured by polyacrylamide gradient gel electrophoresis $(2-16 \%)$ using the methodology described by Nichols et al. [16]. The assignment of LDL subclass phenotypes was based on particle diameter: pattern $\mathrm{A}$, mean diameter $>25.5 \mathrm{~nm}$, and pattern $\mathrm{B}$, predominance of small and dense particles with a mean diameter $\leq 25.5 \mathrm{~nm}[17]$.

Approval was obtained from the relevant institutional review board, and all participants gave their informed consent.

\section{DNA analysis for RFLP detection in LPL}

DNA was extracted from tubes of $15 \mathrm{~mL}$ of blood with EDTA- $K_{3}$, according to the method of Miller et al. [18], and was conserved at $4{ }^{\circ} \mathrm{C}$ until analysis was performed.

N291S was identified after PCR amplification of a 238 bp fragment using the following oligonucleotides: forward 5' GCCGAGATACAATCTTGGTG 3' and reverse 5' CTGCTTCTTTTGGCTCTGACTGT 3'. Such a polymorphism adds a restriction site for the Ava II enzyme. PCR reaction was performed in $25 \mu \mathrm{l}$ total volume containing $0.3 \mathrm{mM}$ of each primer, $0.2 \mathrm{mM}$ of each dNTP, $1 \times$ Taq buffer, $2 \mathrm{mM}$ $\mathrm{MgCl}_{2}, 100 \mathrm{ng}$ of genomic DNA and $2.5 \mathrm{U}$ Taq polymerase (Netzyme) in a Master-Cycler thermocycler (Eppendorf). PCR was performed by means of a touchdown protocol [19] according to the following conditions: an initial denaturation step of 10 minutes at $94^{\circ} \mathrm{C}$ was followed by 4 cycles of 30 seconds at $94^{\circ} \mathrm{C}, 30$ seconds at $60^{\circ} \mathrm{C}$ and 45 seconds at $72^{\circ} \mathrm{C}$. This was followed by 20 cycles of 30 seconds at $94^{\circ} \mathrm{C}, 30$ seconds at $60^{\circ} \mathrm{C}$ minus $0.5^{\circ} \mathrm{C}$ in each cycle and 45 seconds at $72^{\circ} \mathrm{C}$, and then 10 cycles of 30 seconds at $94^{\circ} \mathrm{C}, 30$ seconds at $50^{\circ} \mathrm{C}$ and 45 seconds at $72{ }^{\circ} \mathrm{C}$. The final extension consisted of $10 \mathrm{~min}-$ utes at $72^{\circ} \mathrm{C}$. The PCR product was digested for 4 hours at $37^{\circ} \mathrm{C}$ with Ava II and then analyzed with an $8 \%$ polyacr- 
ylamide gel. If the polymorphism was present, two fragments of 215 and 23 bp (HT+) appeared; if not, the site was destructed in the normal chain, which remained nondigested (238 bp: WT).

\section{Study design}

The study was conducted based on a case-control design. Ninety-three FCHL patients were recruited and matched according to sex and age with a control group of 286 subjects from the general population.

\section{Statistics}

Between-groups comparison was performed using an ANOVA followed by a parametric t-test. Due to skewed distribution of TG, TG analyses were performed on logarithmically transformed values. Statistical analyses were carried out using the Microsoft Excel Data Analysis Package (Microsoft, Inc.).

The Mann-Whitney nonparametric test was used to compare lipid concentrations in FCH patients with pattern A and those with pattern $\mathrm{B}$. To test differences in triglycerides levels, values were logarithmically transformed prior to statistical analysis.

$\chi^{2}$ was performed in order to determine whether populations were in Hardy-Weinberg equilibrium and in order to compare different phenotypes. Significance was set at $\mathrm{p}<$ 0.05 .

Statistic analyses were carried out using the SSPS-15.0 program for Windows (SPSS Inc., Chicago, IL).

\section{Results}

A total of 93 patients, all diagnosed with $\mathrm{FCH}$, were studied: 43 men $(46.3 \%)$ and 50 women $(53.7 \%)$, aged between 15 and 75. 286 subjects from the general population were also studied. Lipid parameters are expressed in Table 1. Significant differences were observed between the two groups in all the variables studied. FCH patients showed higher levels of total cholesterol, triglycerides, LDLc, non-HDLc and apo B100, and lower levels of HDLc, apo A and a smaller LDL diameter.

When non-mutated wild-type (WT) and heterozygote (HT) patients were compared, a smaller average diameter of LDL particles was observed among the latter, with the difference being statistically significant. Table 2 shows the lipid values of pattern A patients compared to those of pattern B patients. FCH patients with pattern B LDL displayed higher concentrations of triglycerides, VLDLc, nonHDLc and apo B100 and lower levels of HDLc than FCH patients with pattern $A$.

Patients with polymorphism presented pattern $\mathrm{B}$ in $87.5 \%$ of cases and pattern $\mathrm{A}$ in $12.5 \%$ of cases, while
Table I: Lipid concentrations in cases ( $\mathrm{FCH}$ patients) and controls.

\begin{tabular}{lccc}
\hline & FCH Patients & Controls & P value* \\
\hline Total cholesterol & $238.67 \pm 50.10$ & $185.13 \pm 28.30$ & 0.001 \\
Triglycerides & $204.71 \pm 192.16$ & $88.27 \pm 42.45$ & 0.001 \\
LDLc & $156.85 \pm 39.97$ & $113.50 \pm 25.20$ & 0.001 \\
HDLc & $47.77 \pm 17.18$ & $53.93 \pm 14.48$ & 0.001 \\
VLDLc & $40.28 \pm 36.52$ & $17.65 \pm 8.49$ & 0.001 \\
Non-HDLc & $192.94 \pm 48.68$ & $131.50 \pm 29.09$ & 0.001 \\
Apo Al & $133.55 \pm 32.52$ & $152.79 \pm 29.03$ & 0.001 \\
Apo Bl00 & $125.80 \pm 28.11$ & $95.25 \pm 21.15$ & 0.001 \\
LDL diameter & $25.45 \pm 0.78$ & $26.14 \pm 0.74$ & 0.001 \\
\hline
\end{tabular}

* ANOVA Test

Values are expressed as mean \pm standard deviation. Units are $\mathrm{mg} / \mathrm{dL}$ in all parameters except LDL diameter $(\mathrm{nm})$.

patients without polymorphism presented pattern A in $69.2 \%$ of cases and pattern B in $30.8 \%$ of cases. These differences were statistically significant $(\mathrm{p}<0.004)$.

N291S polymorphism of LPL occurred in $9.7 \%$ of FCH patients, while no individual in the study sample from the general population presented this mutation. Both samples were in Hardy-Weinberg equilibrium, as the patients showed a $\chi^{2}=0.216$ and $2 \mathrm{p}=0.6423$ and the general population a $\chi^{2}=0$ and $2 \mathrm{p}=1$.

\section{Discussion}

FCH is a disease with a complex phenotype that is not completely understood, and remains difficult to diagnose. This dyslipemic syndrome is associated with disturbances in all lipoprotein fractions. The key underlying abnormality of this condition is elevation of VLDL due to overproduction or defective catabolism [20]. Small and dense LDL is the final expression of this catabolism. These particles are more easily oxidized and display a higher affinity for the extracellular matrix and a higher degree of retention in arterial wall than their larger, normal-sized coun-

Table 2: Lipid concentrations in $\mathrm{FCH}$ patients with pattern $\mathrm{A}$ and pattern B

\begin{tabular}{lccc}
\hline & Pattern A $(n=26)$ & Pattern B $(n=27)$ & P-value* \\
\hline Total cholesterol & $227.88 \pm 41.86$ & $238.03 \pm 50.86$ & 0.450 \\
Triglycerides & $127.80 \pm 65.77$ & $344.55 \pm 234.40$ & 0.001 \\
HDLc & $55.00 \pm 18.54$ & $35.59 \pm 7.94$ & 0.001 \\
LDLc & $147.50 \pm 34.64$ & $149.06 \pm 53.11$ & 0.569 \\
VLDLc & $25.53 \pm 13.11$ & $65.34 \pm 43.71$ & 0.001 \\
Non-HDLc & $172.88 \pm 32.40$ & $202.44 \pm 50.71$ & 0.022 \\
Apo Al & $144.00 \pm 39.87$ & $121.33 \pm 20.49$ & 0.029 \\
Apo BI00 & $118.13 \pm 22.22$ & $133.69 \pm 30.21$ & 0.042 \\
ApoB/ApoA & $0.90 \pm 0.29$ & $1.50 \pm 0.35$ & 0.022 \\
Diameter & $26.06 \pm 0.57$ & $24.86 \pm 0.42$ & 0.001 \\
\end{tabular}

* Mann-Whitney test

Values expressed as mean \pm Standard Deviation. Units are $\mathrm{mg} / \mathrm{dL}$ in all parameters 
terparts [21]. Small and dense LDL has been accepted as an emergent cardiovascular risk factor by the National Cholesterol Education Programme (Adult Treatment Panel III) [22], as many studies have demonstrated that the predominance of these particles is associated with an increase in cardiovascular risk more than classic lipid variables [23,24]. FCH patients with phenotype B of LDL show a clearly atherogenic lipid profile. There is evidence that hypolipidemic treatment can modify the distribution of LDL subclasses [25]. Very high risk patients, including those with this atherogenic lipoprotein profile, may benefit from more potent lipid-lowering therapies [26].

It has been suggested that FCH is a heterogeneous and oligogenic disease [27]. One of the genes likely to exert an influence in this disease is the lipoprotein lipase gene. Many codon polymorphisms of the LPL gene have been described, some of them associated with alterations of the metabolism of triglyceride-rich lipoproteins [28]. One of the most frequent polymorphisms is located in exon 6 (rs268, c. 1128 A>G; N291S) [29]. The prevalence of this mutation in our FCH patients was 9.7\%, which is similar to the $9.3 \%$ described for Dutch FCH patients [5] but considerably higher than the $2-5 \%$ described for other Caucasian populations [30]. No polymorphism was detected in the sample from the general population, which reflects findings in other populations [5] in which no carriers were found, suggesting that the N291S mutation is more frequent among FCH patients. The mutation is likely to affect postprandial lipemia by altering its enzymatic activity [31], resulting in an increase of VLDL particles and high concentrations of apo B100 and leading to the appearance of a greater number of small and dense LDL particles as the final and most important expression of the catabolism of triglyceride-rich lipoprotein particles [32]. In this way, the FCH phenotype of patients with the polymorphism is negatively affected, with altered postprandial responses to fat-rich meals being described, even in patients that were initially normolipemic [33].

These previously published data coincide with our results; polymorphism-carrier patients have been reported to present a smaller LDL diameter, suggesting a clearly atherogenic alteration of the metabolism of triglyceride-rich particles [34]. In fact, in some studies regarding $\mathrm{FCH}$, this polymorphism has been related to patients who had previously presented an ischemic cardiopathy [11].

In our study, patients with the N291S polymorphism showed a smaller average LDL diameter, corresponding with pattern $\mathrm{B}$ and constituting the final expression of the alteration of the metabolism of triglyceride-rich particles. This represents a higher cardiovascular risk among such patients. On the other hand, most patients without this polymorphism had pattern A, constituting a clear differ- ence between both groups. We are aware of the limitations of this study in relation to the number of patients with the polymorphism. Unfortunately, its low prevalence among the general population makes it difficult to conduct a genetic study with a large number of patients that would permit us to draw more solid conclusions. That said, our data show important differences between the two patterns.

In conclusion, $\mathrm{FCH}$ patients with pattern B of LDL show a clearly atherogenic lipid profile. The relationship between small and dense LDL and the presence of the allele encoding for N291S mutation of the LPL gene, present in a high percentage of our FCH patients, could disrupt the phenotype of the disease by altering the clearance of triglyceriderich lipoproteins. Such phenotype expression is the basis for a more atherogenic profile. Therefore, based on our results in $\mathrm{FCH}$ patients in the Autonomous Community of Valencia, the cardiovascular risk of those with pattern B of LDL who carry this polymorphism could be considerably reduced through rigorous treatment of Hyperlipemia.

\section{Abbreviations}

FCH: Familial combined hypermipidemia; LPL: lipoprotein lipase; WT: non-mutated wil-type; HT: Heterzygote.

\section{Competing interests}

The authours declare that they have no competing interests.

\section{Authors' contributions}

AH-M, AL-R and MM-T participated in the design of the study, MJ, AL-R and MM-T carried out the laboratory studies. $\mathrm{CB}$ and $\mathrm{MM}$ performed the statistical analysis and interpretation of data. MC and AL-R carried out the molecular genetic studies. ES and AH-M have been involved in the revision of the manuscript. All authors read and approved the final manuscript.

\section{Acknowledgements}

MC was supported by grant SAF2006-06760 from CICYT, Spain and by a grant from Instituto de Salud Carlos III (Red de Centros FIS-RECAVA RD06/0014/0025).

\section{References}

I. Grundy SM: Hypertriglyceridemia, atherogenic dyslipidemia and the metabolic syndrome. $A m$ J Cardiol 1998, 8I(4A): 18B-25B.

2. Austin MA, King MC, Vranizan KM, Krauss RM: Atherogenic lipoprotein phenotype. A proposed genetic marker for coronary heart disease risk. Circulation 1990, 82:495-506.

3. St-Pierre AC, Cantin B, Dagenais GR, Mauriège $P$, Bernard PM, Després JP, Lamarche B: Low-density lipoprotein subfractions and the long-term risk of ischemic heart disease in men: I3year follow-up data from the Quebec Cardiovascular Study. Arterioscler Thromb Vasc Biol 2005, 25:553-559.

4. Eurlings PM, Kallen CI van der, Geurts JM, van Greevenbroek MM, de Bruin TW: Genetic dissection of familial combined hyperlipidemia. Mol Genet Metab 200I, 74:98-104. 
5. Hoffer MJV, Bredie SJH, Boomsma DI, Reymer PWA, Kastelein JJP, de Knijff P, Demacker PNM, Stalenhoef AFH, Havekes LM, Frants RR: The lipoprotein lipase (Asn29I-Ser) mutation associated with elevated lipid level families with familial combined hyperlipidaemia. Atherosclerosis 1996, I1 9:159-167.

6. Goldstein JL, Schrott HG, Hazzard WR, Bierman EL, Motulsky AG: Hyperlipidemia in coronary heart disease II. Genetic analysis of lipid levels in 176 families and delineation of a new inherited disorder, combined hyperlipidemia. J Clin Invest 1973, 52:1544-1568.

7. Porkka KV, Nuotio I, Pajukanta P, Ehnholm C, Suurinkeroinen L, Syvänne M, Lehtimäki T, Lahdenkari AT, Lahdenperä S, Ylitalo K, Antikainen M, Perola M, Raitakari OT, Kovanen P, Viikari JS, Peltonen L, Taskinen MR: Phenotype expression in familial combined hyperlipidemia. Atherosclerosis 1997, I33:245-253.

8. Ayyobi AF, McGladdery SH, McNeely MJ, Austin MA, Motulsky AG, Brunzell JD: Small, dense LDL and elevated apolipoprotein B are the common characteristics for the three major lipid phenotypes of familial combined hyperlipidemia. Arterioscler Thromb Vasc Biol 2003, 23: I289-I 294.

9. Hu Y, Liu W, Huang R, Zhang $X:$ A systematic review and metaanalysis of the relationship between lipoprotein lipase Asn29/Ser variant and diseases. J Lipid Res 2006, 47:1908-1914.

10. Enerback S, Gimble JM: Lipoprotein lipase gene expression: physiological regulator at the transcriptional and post-transcriptional level. Biochem Biophys Acta 1993, I I 69:107-125.

II. Gerdes C, Fisher RM, Nicaud V, Boer J, Humphries SE, Talmud PJ, Faergeman O: Lipoprotein lipase variants D9N and N29 IS are associated with increased plasma triglyceride and lower high-density lipoprotein cholesterol concentrations: studies in the fasting and postprandial states: the European Atherosclerosis Research Studies. Circulation 1997, 96:733-740.

12. Wittrup HH, Tybjaerg-Hansen A, Abildgaard S, Steffensen R, Schnohr $P$, Nordestgaard BG: A common substitution (Asn29ISer) in Lipoprotein Lipase is associated with increased risk of ischemic heart disease. J Clin Invest 1997, 99:1606-1613.

13. Reymer PW, Groenemeyer BE, Gagné E, Miao L, Appelman EE, Seidel JC, Kromhout D, Bijvoet SM, Oever K van de, Bruin T, Hayden MR, Kastelein JJP: A frequently occurring mutation in the lipoprotein lipase gene (Asn29 ISer) contributes to the expression of familial combined hyperlipidemia. Hum Mol Genet 1995, 4:1543-1549.

14. Bredie SJ, Demacker PN, Stalenhoef AF: Metabolic and genetic aspects of familial combined hyperlipidaemia with emphasis on low-density lipoprotein heterogeneity. Eur J Clin Invest 1997. 27:802-8II.

15. Friedewald WT, Levy RI, Fredrickson DS: Estimation of the concentration of low-density lipoprotein cholesterol in plasma without use of preparative ultracentrifuge. Clin Chem 1972, 18:499-502.

16. Nichols AV, Krauss RM, Musliner TA: Nondenaturing polyacrylamide gradient gel electrophoresis. Methods Enzymol 1986, | 28:4|7-43|.

17. Austin MA, Hokanson JE, Brunzell JD: Characterization of lowdensity lipoprotein subclasses: methodologic approaches and clinical relevance. Curr Opin Lipidol 1994, 5:395-403.

18. Miller SA, Dykes DD, Polesky HF: A simple salting out procedure for extracting DNA from human nucleated cells. Nucleic Acids Res 1988, 16(3): 1215

19. Hecker $\mathrm{KH}$, Roux $\mathrm{KH}$ : High and low annealing temperatures increase both specificity and yield in touchdown and stepdown PCR. Biotechniques 1996, 20:478-485.

20. Adiels M, Olofsson SO, Taskinen MR, Borén J: Overproduction of very low-density lipoproteins is the hallmark of the dyslipidemia in the metabolic syndrome. Arterioscler Thromb Vasc Biol 2008, 28: $1225-1236$.

21. Packard C): Small dense low-density lipoprotein and its role as an independent predictor of cardiovascular disease. Curr Opin Lipidol 2006, 17:4/2-417.

22. Rajman I, Eacho PI, Chowienczyk PJ, Ritter JM: LDL particle size: an important drug target? Br J Clin Pharmacol 1999, 48: I 25-I33.

23. Grundy SM, Cleeman JI, Merz CN, Brewer HB Jr, Clark LT, Hunninghake DB, Pasternak RC, Smith SC Jr, Stone NJ, National Heart, Lung, and Blood Institute; American College of Cardiology Foundation; American Heart Association: Implications of recent clinical trials for the National Cholesterol Education Program Adult Treatment Panel III Guidelines. Circulation 2004, I I 0:227-239.

24. Jarvik GP, Brunzell JD, Austin MA, Krauss RM, Motulsky AG, Wijsman E: Genetic predictors of $\mathbf{F C H}$ in four large pedigrees. Influence of ApoB level major locus predicted genotype and LDL subclass phenotype. Arterioscler Thromb 1994, 14:1687-1694.

25. Nevin DN, Brunzell JD, Deeb SS: The LPL gene in individuals with familial combined hyperlipidemia and decreased LPL activity. Arterioscler Thromb 1994, 14:869-873.

26. Van Bockxmeer FM, Liu Q, Mamotte C, Burke U, Taylor R: Lipoprotein lipase D9N, N29IS and S447X polymorphisms: their influence on premature coronary heart disease and plasma lipids. Atherosclerosis 200I, 157:123-129.

27. Wittekoek ME, Pimstone SN, Reymer PW, Feuth L, Botma GJ, Defesche JC, Prins M, Hayden MR, Kastelein JJ: A common mutation in the lipoprotein lipase (N29 IS) alters the lipoprotein phenotype and risk for cardiovascular disease in patients with familial hypercholesterolemia. Circulation 1998, 97:729-735.

28. Razzaghi H, Day BW, McClure RJ, Kamboh MI: Structure-function analysis of D9N and N29 IS mutations in human lipoprotein lipase using molecular modelling. J Mol Graph Model 200I, 19: 487-494, 587-590.

29. Georgieva AM, van Greevenbroek MM, Krauss RM, Brouwers MC, Vermeulen VM, Robertus-Teunissen MG, Kallen CJ van der, de Bruin TW: Subclasses of low-density lipoprotein and very low-density lipoprotein in familial combined hyperlipidemia: relationship to multiple lipoprotein phenotype. Arterioscler Thromb Vasc Biol 2004, 24:744-749.

30. Pimstone SN, Clee SM, Gagne SE, Miao L, Zhang H, Stein EA, Hayden MR: A frequently occurring mutation in the lipoprotein lipase gene (Asn29 ISer) results in altered postprandial chylomicron triglyceride and retinyl palmitate response in normolipidemic carriers. J Lipid Res 1996, 37:1675-1684.

31. Hopkins PN, Heiss G, Ellison RC, Province MA, Pankow JS, Eckfeldt $\mathrm{JH}$, Hunt SC: Coronary artery disease risk in familial combined hyperlipidemia and familial hypertriglyceridemia: a casecontrol comparison from the National Heart, Lung, and Blood Institute Family Heart Study. Circulation 2003, 108:519-523.

32. National Cholesterol Education Program (NCEP): Expert Panel on Detection, Evaluation, and Treatment of High Blood Cholesterol in Adults (Adults Treatment Panel III): Third Report of the National Cholesterol Education Program (NCEP): Expert Panel on Detection, Evaluation, and Treatment of High Blood Cholesterol in Adults (Adults Treatment Panel III) final report. Circulation 2002, 106:3 I43-342I.

33. Vakkilainen J, Steiner G, Ansquer JC, Aubin F, Rattier S, Foucher $\mathrm{Ch}$, Hamsten A, Taskinen MR, DAIS Group: Relationships between low-density lipoprotein particle size, plasma lipoproteins, and progression of coronary artery disease: the Diabetes Atherosclerosis Intervention Study (DAIS). Circulation 2003, 107:1733-1737.

34. Hurt-Camejo E, Camejo G, Sartipy P: Phospholipase A2 and small, dense low-density lipoprotein. Curr Opin Lipidol 2000, I I:465-47|

Publish with Bio Med Central and every scientist can read your work free of charge

"BioMed Central will be the most significant development for disseminating the results of biomedical research in our lifetime. "

Sir Paul Nurse, Cancer Research UK

Your research papers will be:

- available free of charge to the entire biomedical community

- peer reviewed and published immediately upon acceptance

- cited in PubMed and archived on PubMed Central

- yours - you keep the copyright 